\title{
INTRALINGUAL CONNECTION BETWEEN THE NOVEL TEXT AND ITS FILM ADAPTATION: THE EMOTIONAL ASPECT
}

\author{
Ekaterina V. Nesmachnova \\ Volgograd State University, Volgograd, Russia
}

\begin{abstract}
This paper is devoted to studying intralingual connection between the novel text and its film adaptation: explication means of an emotional condition of the main character of the novel Perfume: The Story of a Murderer (Patrick Süskind. Das Parfum. Die Geschichte eines Mörders) by P. Suskind and its German-language version with the same name directed by Tom Tykwer are analyzed. The object of the research is the verbal and nonverbal means of emotion explication associated with the implementation of the 'smell' concept that is a basic one in this novel. As a result of a comparative analysis of the novel fragments and the corresponding film action, it is established that when the film version is created, the original literary text is transformed, which actualizes the possibilities of non-verbal communication: the verbal series is supplemented with audio and visual content. It is shown that the revealed transformations change the emotional space of the literary text: hatred, which is the dominant of the emotional state of the main character in the novel, is replaced in the film version by positive (tenderness, love) and unintentionally negative (sadness, regret) emotions. Cinematographic tools selected for intralingual translation shift the focus of the character's perception expanding and changing his psychological portrait in the movie; positive emotions "humanize" the central character causing compassion in the viewer.

Key words: text, film text, emotions, film adaptation, transformation, verbal communication, nonverbal communication.

Citation. Nesmachnova E.V. Intralingual Connection Between the Novel Text and Its Film Adaptation: the Emotional Aspect. Vestnik Volgogradskogo gosudarstvennogo universiteta. Seriya 2, Yazykoznanie [Science Journal of Volgograd State University. Linguistics], 2018, vol. 17, no. 3, pp. 189-194. (in Russian). DOI: https:// doi.org/10.15688/jvolsu2.2018.3.20
\end{abstract}

\section{ОСОБЕННОСТИ ВЫРАЖЕНИЯ ИНТРАЯЗЫКОВОЙ СВЯЗИ ЛИТЕРАТУРНОГО ПРОИЗВЕДЕНИЯ И ЕГО ЭКРАНИЗАЦИИ: ЭМОЦИОНАЛЬНЫЙ АСПЕКТ}

\author{
Екатерина Владимировна Несмачнова \\ Волгоградский государственный университет, г. Волгоград, Россия
}

\begin{abstract}
Аннотация. Статья посвящена изучению интраязыковой связи художественного текста и его экраниза$\infty$ ции: анализируются средства экспликации эмоционального состояния главного героя романа П. Зюскинда ¿ิ «Парфюмер. История одного убийцы» (Patrick Süskind. Das Parfum. Die Geschichte eines Mörders) и ๓ं немецкоязычной версии одноименного фильма режиссера Тома Тыквера (Tom Tykwer). Объектом исследогі вания выступают вербальные и невербальные средства выражения эмоций, которые в сознании главного героя неизменно связаны с запахами. В результате сопоставительного анализа фрагментов романа и соответствующих им киносцен установлено, что при создании киноверсии происходит трансформация исходного литературного текста, актуализирующая возможности невербальной коммуникации: вербальный 플 ряд дополнен аудио- и визуальным содержанием. Показано, что выявленные трансформации изменяют эмотивное пространство художественного текста: ненависть как доминанта эмоционального состояния глав-
\end{abstract}




\section{МАТЕРИАЛЫ И СООБЩЕНИЯ}

ного героя в романе заменяется в киноверсии положительными (нежность, любовь) и неинтенсивными отрицательными (скорбь, грусть, сожаление) эмоциями. Кинотекстовые средства, избранные для интраязыкового перевода, смещают фокус восприятия персонажа, расширяя и изменяя его психологический портрет в кинофильме; положительные эмоции «очеловечивают» героя, вызывая сострадание у зрителя.

Ключевые слова: текст, кинотекст, эмоции, экранизация, трансформация, вербальная коммуникация, невербальная коммуникация.

Цитирование. Несмачнова Е. В. Особенности выражения интраязыковой связи литературного произведения и его экранизации: эмоциональный аспект // Вестник Волгоградского государственного университета. Серия 2, Языкознание. -2018. - Т. 17, № 3. - C. 189-194. - DOI: https://doi.org/10.15688/jvolsu2.2018.3.20

\section{Кино и литература: специфика взаимосвязи}

В эпоху глобализации и технического прогресса визуализация современной культуры стала отражением стремления к скорости и полноте восприятия. Книга уходит на второй план в дискурсе развлечений, ее вытесняют кинофильмы и медиатексты. Кинематограф и телевидение служат источниками большинства цитат, крылатых выражений и клише, функционирующих в повседневной коммуникации. Социокоммуникативное пространство представляет собой сложную систему, в которой «сохраняются и транслируются знаки культуры» [Митягина, 2007, с. 104]. При этом, по словам В.А. Митягиной, культура проявляет себя как феномен коммуникации, поэтому кинематограф может рассматриваться как знаковая система, объединяющая достижения цивилизации с духовным и художественным потенциалами современного социума.

Кинематограф несет специфическую для эпохи и культуры нагрузку и реализует функции средств массовой коммуникации. Кинофильм обладает возможностью абсолютно овладевать сознанием людей, погружая их в свою реальность и управляя их эмоциями. Качество фильма определяется интерпретациями воспринимающих его субъектов, их количеством и разнообразием. Экранизация осознается зрителями как единственно возможная вторичная реальность [Кудрявцева, 2014, с. 58].

Произведение художественной литературы и кинофильм, созданный на его основе, не являются взаимозаменяемыми, что объясняет возможность экранизации литературных произведений: она, по утверждению Г.Г. Слышкина, неосуществима при абсолютной чуждости кино и литературы и бессмысленна при полном их совпадении [Слышкин, Ефремова, 2004, с. 30].
Сопоставительный анализ текстов литературных произведений и скриптов экранизаций берет свое начало с момента появления полнометражных звуковых фильмов, он широко использовался киноведами и режиссерами для осмысления особенностей взаимодействия кино и литературы, прежде всего, объективных закономерных трансформаций литературного произведения в процессе и в результате его экранизации.

Этой теме посвящено большое количество публикаций, что свидетельствует об исследовательском интересе к данной проблематике, а многие работы 1920-1930-х гг. таких лингвистов, как Н.Д. Анощенко, А.И. Пиотровский, Ю.Н. Тынянов, В.Б. Шкловский, и сегодня не утратили теоретической значимости. Экранизацию, в которой основной целью является создание эквивалента художественного произведения, принято считать оптимальной. Ю.М. Лотман в своей работе «Семиотика кино и проблемы киноэстетики» писал о том, что перевод литературного произведения на язык кино должен осуществляться с сохранением содержания, духа и слова [Лотман, 1998]. При этом до сих пор не существует системы критериев, позволяющих полно охарактеризовать отношения экранизации и литературного произведения как первоисточника.

Цель нашего исследования заключается в выявлении особенностей формирования содержательного плана экранного эквивалента литературного произведения на примере передачи эмоционального состояния главного героя романа П. Зюскинда «Парфюмер. История одного убийцы» (Patrik Süskind. Das Parfum. Die Geschichte eines Mörders) и немецкоязычной версии одноименного фильма режиссера Тома Тыквера (Tom Tykwer). 


\section{Специфика выражения эмоций}

в романе П. Зюскинда

«Парфюмер. История одного убийцы»

Средства выражения эмоций бывают двух видов: вербальные и невербальные (жесты, мимика, интонации, паузы, смех и т. д.), способные не только дополнить или усилить словесное выражение эмоций, но иногда и заменить его.

Внешнее поведение отражает внутреннее душевное состояние индивида, которое распознается по отдельным движениям рук и тела в целом, наклону головы, взгляду, выражению лица, интонации и модуляции голоса. Из этого следует, что слова, произносимые им, воспринимаются другим участником коммуникации в соответствии с тем, как именно они были сказаны, а не с тем, что было сказано.

Изучению внешних проявлений внутреннего состояния индивида посвящена фундаментальная работа Г.Е. Крейдлина «Невербальная семиотика: язык тела и естественный язык», в которой выделяется десять дисциплин современной невербальной семиотики [Крейдлин, 2002, с. 22]. Наше исследование находится в русле четырех из них, а именно: паралингвистики (науки о звуковых кодах невербальной коммуникации), кинесики (науки о жестах и жестовых движениях), аускультации (науки о слуховом восприятии звуков и аудиальном поведении людей в процессе коммуникации) и ольфакции (науки о языке запахов, смыслах, передаваемых с помощью запахов, и роли запахов в коммуникации). Особую значимость для нашего исследования приобретают достижения ольфакции, поскольку специфика выражения эмоций в исследуемом романе связана с тем, что в качестве единственного средства выражения эмоций главного героя избран запах. С помощью своего уникального обоняния Жан-Батист Гренуй способен уловить любой запах, находящийся даже на дальнем расстоянии, а также разобрать его в своем сознании на составляющие и смешать с другими ароматами. Слова для Гренуя слишком скудны, они не способны выразить даже половины его эмоций, это подвластно лишь ароматам, в мир которых погружен главный герой.

\section{Сходства и различия средств выражения эмоционального состояния \\ главного героя в романе \\ и его экранизации}

Эмотивное пространство текста формируется переживаниями автора и персонажа. Чувства, приписываемые П. Зюскиндом герою, являются объективными, а чувства, испытываемые автором и выражаемые им, носят субъективный характер. В контексте целого произведения эмоциональная структура персонажей имеет лишь относительную независимость от автора. Целостное эмотивное содержание предполагает обязательную интерпретацию мира человеческих эмоций и его оценку с позиции автора с целью воздействия и преобразования. В художественной литературе имеет место двойная психология: персонажей и автора, которые находятся в сложных отношениях, заключающихся в эмотивных смыслах, включенных в структуру образа персонажа и автора [Бабенко, Казарин, 2003 , с. 122]. Эмоции Жан-Батиста Гренуя являются особой психической реальностью. Их совокупность отражает внутренний мир героя.

Эмоциональной кульминацией романа становится казнь героя. Описание этого события в романе и визуальное воспроизведение данной сцены на экране являются яркими примерами, демонстрирующими сходства и различия в использовании средств выражения эмоций.

Композиционное сходство обнаруживается в сцене прибытия Гренуя на собственную казнь. Главный герой, нанеся на себя неповторимые духи, содержащие запахи 25 невинных девушек, вызывает у толпы эмоциональный восторг:

(1) Der Mann, der auf dem Richtplatz stand, war die Unschuld in Person. Das wußten in diesem Moment alle. Es überkam sie ein mächtiges Gefühl von Zuneigung, von Zärtlichkeit, von toller kindischer Verliebtheit, von Liebe zudem kleinen Mördermann, und sie konnten, sie wollten nichts dagegen tun. Sie liebten ihn (Süskind, S. 285) / Человек, стоявший на лобном месте, был воплощенная невинность. В тот момент это знали все. Их захлестнуло чувство влечения, нежности, безумной детской влюбленности, любви к маленькому злодею, и они не могли, не хотели ему сопротивляться. Они любили его (Зюскинд, с. 94). 


\section{МАТЕРИАЛЫ И СООБЩЕНИЯ}

Аромат, созданный Гренуем, был столь совершенен, что вызывал только самые возвышенные и искренние чувства: нежность, влюбленность и, главное, любовь. Лексема Liebe, ее производные Verliebtheit, liebten, как и номинации других высоких и нежных чувств Zuneigung, Zärtlichkeit, направленно эксплицируют эмоции толпы.

В фильме данные чувства переданы следующим образом: люди в воскресных нарядах собрались, чтобы увидеть жесточайшую казнь самого ужасного убийцы, однако со слезами и с криками, что перед ними настоящий ангел, которого они безумно любят, становятся на колени. В романе сказано, что Греную достаточно было нанести на себя необыкновенный аромат, чтобы вызвать такой восторг, в фильме же для усиления эффекта используется музыкальное сопровождение, которое создает неоднозначный эмоциональный фон, а также надушенный платок: Гренуй наносит одну каплю духов на платок и сначала взмахивает им так, чтобы аромат, который показан как легкое золотистое свечение, развеялся по воздуху, затем отпускает платок - он летит прямо в толпу, и люди, вдохнув аромат, падают, будто разом лишившись чувств, а потом предаются плотским утехам.

Передача содержания сцены казни Гренуя на экране, несмотря на множество схожих моментов, связана с рядом трансформаций, повлиявших на изменение характера, эмоционального потенциала героя и восприятия его зрителями.

В фильме Гренуй способен вызвать к себе жалость и сострадание (Unschuld in Person), чего нельзя сказать о литературном персонаже - главный герой романа испытывает только ненависть и желает вызывать ее у людей по отношению к себе:

(2) Grenouille stand und lächelte. Aber es war in Wirklichkeit kein Lächeln, sondern ein häßliches, zynisches Grinsen, das auf seinen Lippen lag und das seinen ganzen Triumph und seine ganze Verachtung widerspiegelte. Er erlebte in diesem Augenblick den größten Triumph seines Lebens. Und er wurde ihm fürchterlich, denn er konnte keine Sekunde davon genießen. Was er sich immer ersehnt hatte, daß nämlich die ändern Menschen ihn liebten, wurde ihm im Augenblick seines Erfolges unerträglich, denn er selbst liebte sie nicht, er haßte sie. Und plötzlich wußte er, daß er nie in der Liebe, sondern immer nur im $\mathbf{H a \beta}$ Befriedigung fände, im Hassen und Gehaßt werden (Süskind, S. 289-290) / Гренуй стоял и улыбался. Но в действительности не улыбка, а гадкая, циничная ухмылка змеилась на его губах, отражая весь его триумф и все его презрение. В этот миг он пережил величайший триумф своей жизни. И он ужаснулся, ибо ни секунды не смог им насладиться. То, чего он всегда так страстно желал, а именно чтобы его любили другие люди, в момент успеха стало ему невыносимо, ибо он сам не любил их, он их ненавидел. И внезапно он понял, что никогда не найдет удовлетворения в любви, но лишь в ненависти своей к людям и людей к себе (Зюскинд, с. 95-96).

(3) Er wollte ein Mal, nur eineinziges Mal, ins einer wahren Existenz zur Kenntnis genommen warden und von einem anderen Menschen eine Antwort erhalten auf sein einziges wahres Gefühl, den Haß (Süskind, S. 291) / Он хотел один раз, всего один-единственный раз, быть воспринятым в своей истинной сути и получить от людей отклик на свое единственное истинное чувство - ненависть (Зюскинд, с. 96).

Рефреном в описании эмоционального состояния Гренуя в тексте романа выступает инициальное для лексического ряда слово Наß: einhäßliches, zynisches Grinsen, er haßte sie, im Hassen und Gehaßt werden.

Изначальным желанием Гренуя было добиться любви людей, впоследствии оно понимается им как ложное, на самом деле он стремится добиться ненависти, однако это уже невозможно, так как его духи не способны вызывать негативные эмоции. Впервые Гренуй проявляет и осознает единственное чувство, которое он способен испытывать, - ненависть (Наß). Текст романа насыщен негативными чувствами главного героя, однако в фильме они заменены на положительные (нежность (Feinheit) и любовь (Liebe)) и другие менее интенсивные отрицательные (скорбь (Kummer), грусть (Traurigkeit) и сожаление (Bedauern)), представленные средствами невербальной коммуникации и характеризующие больше внутреннее состояние героя, чем его отношение к другим людям. В фильм добавлена яркая сцена романтических фантазий Гренуя о его первой жертве, чей аромат он всегда помнит. Герой представляет себя вместе с девушкой со сливами: он берет ее за руку, 
она обнимает его и затем они нежно целуются, но следом показана сцена, где она мертва, а по щекам Гренуя катятся слезы - свидетельство его скорби и сожаления об утрате не только аромата, но и самой девушки. Сцена выражает желание Гренуя любить и быть любимым. В этом искреннем и чистом желании обычного человека, представленном в фильме, заключается главное отличие кинообраза Гренуя от его исходного образа в романе. В экранизации произведения происходит изменение характера главного героя, осуществляемое посредством приема модуляции как адекватной замены: описанный в книге туман, представленный как запах самого героя (Der Nebel war sein eigener Geruch / Туман был его собственным заnахом), удушающий по своей природе и неопределенный для его обладателя, является слишком абстрактным для его правильного восприятия зрителем.

\section{Выводы}

Таким образом, в результате сравнения фрагментов романа с кинотекстом, включающим в себя визуальный ряд как совокупность средств невербальной коммуникации (жестов, мимики, плача, восклицаний), а также музыку, создающую определенную атмосферу, и т. д., можно констатировать, что доминантой эмоционального состояния главного героя в романе является ненависть (Наß), которая в экранизации была заменена на положительные и неинтенсивные отрицательные эмоции. Экспликация последних в киноверсии романа осуществляется с помощью трансформаций, которые предполагают использование, прежде всего, средств невербальной коммуникации. Кинотекстовые приемы, избранные для интраязыкового перевода, смещают фокус восприятия персонажа, расширяя и изменяя его психологический портрет в кинофильме. Средства выражения эмоционального состояния Гренуя в фильме частично изменяют знак переживаемой им эмоции, при этом положительные эмоции «очеловечивают» главного героя, вызывая сострадание у зрителей и в какой-то степени оправдывая его жестокость.

\section{СПИСОК ЛИТЕРАТУРЫ}

Бабенко Л. Г., Казарин Ю. В., 2003. Лингвистический анализ художественного текста. Теория и практика. М. : Флинта : Наука. 496 с.

Крейдлин Г. Е., 2002. Невербальная семиотика: язык тела и естественный язык. М. : Новое литературное обозрение. 592 с.

Кудрявцева Е. Л., 2014. Общество как «контекст» произведения искусства и феномен цитирования из художественных кинофильмов в связи с понятием национальной личности // Becтник Российского университета дружбы народов. Серия: Вопросы образования: языки и специальность. № 4. С. 58-66.

Лотман Ю. М., 1998. Семиотика кино и проблемы киноэстетики // Об искусстве. СПб. : Искусство-СПБ. С. 288-373.

Митягина В. А., 2007. Социокультурные характеристики коммуникативного действия : монография. Волгоград : Изд-во ВолГУ. 356 с.

Слышкин Г. Г., Ефремова М. А., 2004. Кинотекст (опыт лингвокультурологического анализа). М. : Водолей Publishers. 153 c.

\section{ИСТОЧНИКИ}

Зюскинд - Зюскинд П. Парфюмер. История одного убийцы. СПб. : Азбука-классика, 2002. $101 \mathrm{c}$.

Süskind-Süskind P. Das Parfüm. Die Geschichte eines Mörders. Zürich : Diogenes Verlag AG, 1985. $306 \mathrm{~S}$.

Das Parfum. Die Geschichte eines Mörders [The feature film «Perfume: The Story of a Murderer»], 2006. URL: https://kat.cr/das-parfum-die-geschichteeines-mrders-2006-t740524.html (Accessed 28 September 2016).

\section{REFERENCES}

Babenko L.G., Kazarin Yu.V., 2003. Linguistic analysis of literary text. Theory and practice. Moscow, Flinta; Nauka Publ. 496 p.

Kreydlin G.E., 2002. Nonverbal semiotics: Body language and natural language. Moscow, Novoe literaturnoe obozrenie Publ. 592 p.

Kudryavtseva E.L., 2014. Society as a "context" of art production and the phenomenon of feature films citation in connection with the notion of national identity. Vestnik Rossiyskogo universiteta druzhby narodov. Seriya: Voprosy obrazovaniya: yazyki i spetsialnost [Bulletin of of Peoples' Friendship University of Russian. 


\section{МАТЕРИАЛЫ И СООБЩЕНИЯ}

Series: Problems of Education: Languages and Specialty], no. 4, pp. 58-66.

Lotman Yu.M., 1998. Semiotics of cinema and problems of cinema aesthetics. Ob iskusstve. Saint Petersburg, Iskusstvo-SPB Publ. pp. 288-373.

Mityagina V.A., 2007. Sociocultural characteristics of communicative action. Volgograd, Izd-vo VolGU, 2007.356p.

Slyshkin G.G., Efremova M.A., 2004. Film text: the experience of linguistic and cultural analysis. Moscow, Vodoley Publishers. 153 p.

\section{SOURCES}

Suskind P., 2002. Perfume. The Story of a Murderer. Saint Petersburg, Azbuka-klassika Publ. 101p. (in Russian)

Süskind P., 1985. Das Parfüm. Die Geschichte eines Mörders. Zürich, Diogenes Verlag AG, 1985.306 p. The feature film: Das Parfum. Die Geschichte eines Mörders. 2006. URL: https://kat.cr/das-parfumdie-geschichte-eines-mrders-2006-t740524.html (accessed 28 September 2016).

\section{Information about the Author}

Ekaterina V. Nesmachnova, Postgraduate Student, Department of Translation Studies, Volgograd State University, Prosp. Universitetsky, 100, 400062 Volgograd, Russia, nesmachnova@volsu.ru, https:// orcid.org/0000-0002-5316-9040

\section{Информация об авторе}

Екатерина Владимировна Несмачнова, аспирант кафедры теории и практики перевода, Волгоградский государственный университет, просп. Университетский, 100, 400062 г. Волгоград, Россия, nesmachnova@volsu.ru, https://orcid.org/0000-0002-5316-9040 